\title{
Fenonomia e Isonomia no Contexto da Modernidade: Possibilidades de um Novo Modelo Social para as Organizações
}

\section{Fenonomy and Isonomy in the Modernity Context: Opportunities for a New Social Model for Organizations}

\author{
Marcio Jacometti \\ Universidade Tecnológica Federal do Paraná/Campus Cornélio Procópio - PR \\ marcio.jacometti@gmail.com \\ Belmiro Valverde Jobim Castor \\ Pontifícia Universidade Católica do Paraná - PUC PR \\ belmirocastor@gmail.com \\ Daniel Moraes Pinheiro \\ Universidade Federal de Santa Catarina - UFSC \\ daniel.m.pinheiro@gmail.com \\ João Pereira de Castilho Filho \\ Universidade Federal do Paraná - UFPR \\ pereiracastilho@hotmail.com
}

Submissão: 08/11/2011

Aprovação: 19/01/2013

\section{Resumo}

Este trabalho lida com duas categorias centrais da Teoria da Delimitação dos Sistemas Sociais proposta por Ramos (1989): as fenonomias e as isonomias. Juntas, elas estabelecem o chamado paradigma paraeconômico da organização social. Ao caracterizar estes dois modelos, o artigo revisa seus conceitos fundamentais para explicar as causas e consequências da combinação destas categorias como alternativa ao modelo econômico moderno fundado na racionalidade formal. A partir da lógica inerente à racionalidade substantiva, o texto propõe estudos sobre como as organizações de setores diferenciados adotam ou não princípios da fenonomia e isonomia em suas práticas, motivadas por pressões ambientalistas e sociais. Pela noção de homem parentético, sugere-se que, além do conflito entre modelos na estrutura social, existe também o conflito ao nível do indivíduo que se submete ao modelo de homem econômico, abrindo mão da realização pessoal. De modo reativo a essa realidade, observa-se o surgimento de muitas organizações que se baseiam em valores distintos dos da racionalidade instrumental como é o caso das organizações de economia social. Contudo, é necessário investigar estas questões para se compreender até que ponto essa combinação é realmente um modelo social que está sendo adotado em alguns setores da economia.

Palavras-chave: fenonomia, isonomia, organizações de economia social, homem parentético. 


\begin{abstract}
This article deals with two central categories of the Theory of Social Systems Delimitation proposed by Ramos: the fenonomies and the isonomies. Together, they would establish the so-called paraeconomic paradigm of social organization. By characterizing these two models, the paper reviews their important concepts, to explain the causes and consequences of the combination of these categories as an alternative to modern economic model based on formal rationality. From the inherent logic of substantive rationality, the text proposes studies on how different organizations adopt fenonomy and isonomy principles in their practices, moved by environmental and social pressures. The concept of parenthetic man implies that in addition to a conflict between models in the social structure, there is also the conflict at the individual label who submits to the model of economic man, giving up personal fulfillment. Reactively to this reality, it observes the emergence of many organizations that are based on distinct values of the values of instrumental rationality as is the case of social economy organizations. However, it is necessary to investigate these issues to understand to what extend to which this combination is really a social model that is being adopted in some sectors of the economy.
\end{abstract}

Key-words: fenonomy, equality, social economy organizations, parenthetical man. 


\section{Introdução}

O sistema produtivo da modernidade é cerceado por contínuos questionamentos em função das externalidades negativas que impõe à sociedade. Diante disso, busca-se com frequência a construção de uma nova imagem mediante uma racionalidade orientada em valores mais equilibrados na sua relação com a sociedade. $O$ presente artigo resgata a discussão sobre que valores deveriam ser adotados para que efetivamente ocorra uma transição da economia baseada puramente na eficiência para um modelo que leve em conta a sustentabilidade do sistema econômico a longo prazo. É preciso, portanto, repensar o modelo econômico atual sob a ótica da sustentabilidade.

A análise é realizada a partir dos conceitos propostos ao longo do trabalho de Alberto Guerreiro Ramos (1989). Imergindo em sua obra, alguns conceitos trabalhados apresentam interessante relação: a ênfase na busca da racionalidade substantiva como orientadora das ações humanas e sociais, o conceito de indivíduo parentético proposto por Ramos e os dois tipos de organizações produtivas alternativos às organizações econômicas convencionais que ele denominou de isonomias e fenonomias.

Assim, torna-se necessário investigar como os valores individuais tornam-se expressões da coletividade num contexto sócio-econômico. Trata-se de compreender a capacidade do indivíduo não em combater, mas de mostrar realidades alternativas onde seja possível um ganho que extrapole o entendimento econômico. Portanto, este estudo propõe-se também a dar continuidade à linha de estudos em racionalidade e economia social, tendo como foco as problemáticas do campo da gestão, trazendo à tona uma discussão relevante sobre o comportamento dos gestores em organizações de importante relevância sócio-econômica.

O objetivo é, portanto, apresentar relações conceituais e práticas, interessantemente provocadoras, entre o indivíduo parentético, a racionalidade substantiva e a noção de fenonomia/isonomia, fortalecendo a importância da dimensão social da sustentabilidade em modelos que necessitem de autonomia financeira. A questão que se coloca é se seria possível conciliar a lógica fenonômica/isonômica com a econômica. A dimensão social da sustentabilidade em organizações de economia social tem seus conceitos calcados na concepção substantiva da economia e poderia sim ser um caso. Princípios, como o da reciprocidade, possuem relações com as expressões substantivas do indivíduo. Poucos estudos empíricos têm sido realizados para identificar em que setores da economia prevalecem o modo racional substantivo.

Jerônimo et al. (2003) detectaram que a finalidade principal de uma cooperativa é a melhoria da condição econômico-social de seus cooperados. Nesse sentido, o objetivo seria a prestação de serviços aos seus associados e não o lucro. Nas sociedades centradas no mercado, com o predomínio da razão instrumental, são significativos os desafios às formas de organização em que a interação simbólica e a autogestão são fundamentais, conforme prevê a Teoria da Delimitação de Sistemas Sociais e as categorias de fenonomia e isonomia de Ramos (1989). As cooperativas seriam, assim, concebidas como sistemas sociais peculiares, em que os conflitos políticos seriam, em princípio, assumidos e não abafados, como pode acontecer em organizações que visam fundamentalmente o lucro (AKTOUF, 1996).

Outro trabalho empírico realizado nesta perspectiva foi feito por Fraga (2000) que trata da possibilidade de as empresas produtivas possuírem elementos característicos das organizações substantivas, tendo como perspectiva geral a construção de um ambiente organizacional integrativo, com base na teoria da ação comunicativa de Habermas (1987a, 1987b) e na noção de racionalidade substantiva contida em Weber 
(1994). Ramos (1989) detectou que duas das quatro formas de racionalidade identificadas por Weber - substantiva e instrumental - coexistem no cotidiano de uma organização produtiva, embora em intensidades diferentes.

Segundo Serva (1996), as organizações podem contemplar em seu cotidiano, tanto a presença da razão substantiva quanto da instrumental e, portanto, as duas formas de ação social delas resultantes, poderão coexistir nos processos e nas dinâmicas organizacionais. Aquilo que irá variar é justamente o grau de predominância de uma ou outra forma de ação social.

Tais proposições conceituais associadas ao modelo paraeconômico de Ramos (1989) e suas considerações acerca do indivíduo parentético, aparentam ter relação complementar e direta, especialmente consideradas as observações de Serva (1997c) quando da exposição da ação racional substantiva. Portanto, propõe-se neste trabalho a reflexão sobre a seguinte problemática: até que ponto o conceito de indivíduo parentético explica a dimensão social da sustentabilidade em organizações de economia social? E qual seria a implicação do modelo fenonômico/isonômico para o principio do prazer e do sofrimento no trabalho? Na próxima seção, procura-se dimensionar uma metodologia que possibilite alcançar as respostas a estas questões de pesquisa.

\section{Metodologia}

Esta pesquisa caracteriza-se como um estudo exploratório na medida em propõe uma investigação sobre a evolução do modelo fenonômico/isonômico em alguns setores da economia face às pressões ambientalistas e por maior realização do homem no trabalho. Segundo Santos (1991) a pesquisa exploratória é o contato inicial com o tema a ser analisado, com os sujeitos a serem investigados e com as fontes secundárias disponíveis. O pesquisador adota uma atitude receptiva às informações da realidade social e uma postura flexível. Para Sampieri et al. (1991), os estudos exploratórios servem para aumentar o grau de familiaridade com fenômenos relativamente desconhecidos, obter informações sobre a possibilidade de levar adiante uma investigação mais completa sobre um contexto particular e estabelecer prioridades para investigações posteriores. Caracterizam-se, portanto, por serem mais flexíveis em sua metodologia em comparação com os estudos descritivos ou explicativos, sendo mais amplos e dispersos.

Da mesma forma, Tripodi et al. (1975) afirmam que os estudos exploratórios são baseados na pressuposição de que por meio do uso de procedimentos relativamente sistemáticos, pode-se desenvolver hipóteses relevantes a um determinado fenômeno, para serem testadas mediante estudos empíricos posteriores.

Como os métodos de pesquisa aplicáveis à pesquisa exploratória são diferentes daqueles aplicáveis à pesquisa conclusiva, é necessário que o pesquisador tenha os objetivos do estudo firmemente estruturados quando planeja a pesquisa. "Enquanto procura por hipóteses, a pesquisa exploratória é apropriada; quando as hipóteses já foram estabelecidas e devem ser testadas, a pesquisa conclusiva é necessária" (BOYD et al., 1989, p. 92).

O trabalho de campo deve então ser planejado de modo a contemplar alguns setores da economia. Uma possibilidade seria selecionar grupos de gestores enquanto unidades de análise, de modo a contemplar organizações de economia social, o setor educacional, cooperativas e um setor de economia tradicional. A investigação poderia ser realizada mediante a aplicação de questionário estruturado para possibilitar a realização de testes estatísticos entre as visões de cada grupo em relação à racionalidade, à isonomia e à fenonomia e, numa segunda etapa, aplicar entrevistas em 
profundidade com alguns dirigentes de modo a buscar explicar eventuais divergências. A avaliação da intensidade da convergência ou divergência sobre as categorias de análise entre níveis abre uma seara promissora para os estudos organizacionais.

\section{A Influência das Organizações de Economia Social}

De acordo com Gonçalves (1996, p. 23), as Organizações NãoGovernamentais $^{1}$ (ONGs) podem ser descritas como organizações formais sem fins lucrativos, com alguma autonomia, que realizam projetos e programas da área de política de desenvolvimento. O surgimento destas organizações pode ser analisado junto ao contexto do Terceiro Setor. Uma das hipóteses é se tais organizações possuem mais características que convergem com princípios básicos da isonomia/fenonomia do que econômicos.

Nesse sentido, estas organizações estariam mais bem preparadas para obter sucesso na solução de problemas sociais devido a falhas do Estado ou do mercado, uma vez que estas atuariam em pequena escala, com maior flexibilidade e capacidade de canalizar a participação popular (SALAMON, 1998; GONÇALVES, 1996). De acordo com Gonçalves (1996), as organizações de economia social pertencem ao âmbito da chamada sociedade civil, a qual é colocada como uma esfera entre o mercado e o Estado. Seriam, nesse sentido, "mecanismos preferenciais" que atuariam para prover a sociedade de determinados "bens coletivos sociais".

Outra característica fundamental das organizações de economia social é a relação de solidariedade que elas mantêm com a sociedade. Influenciam políticas governamentais e promovem a mobilização da sociedade em busca da democratização (GONÇALVES, 1996; FERNANDES, 1994; LANDIM e DURÃO, 2010).

No Brasil, a origem das organizações de economia social remonta à segunda metade dos anos 1970, quando estas passam a ser concebidas como uma nova forma de organização social. Assumindo, num primeiro momento, o papel de assessoras e/ou mediadoras de movimentos sociais, tendo como objetivo principal a promoção social em diversos setores. Durante os anos 1980 e 1990, vários foram os estudos que adotaram as organizações de economia social como objetos de análise e, para definirem seu conceito, consideraram as especificidades das mesmas, ressaltando o que elas não são, para então apresentar as características atribuídas a elas e afirmar aquilo que são.

Nos anos 1970, a posição política da maioria dessas organizações era de esquerda (LANDIM, 1996) e entre seus fundadores e primeiros articuladores encontravam-se exilados políticos e pessoas relacionadas a instituições religiosas e de educação de base. Huber (1985) tem importantes ressalvas em sua obra acerca das questões de alinhamento político e suas relações para com os enclaves presentes nestes movimentos. Este autor expunha acerca dos chamados movimentos alternativos, com uma característica diferenciadora dos demais movimentos sociais, das quais seus participantes possuem "o critério subjetivo da reciprocidade, do sentir-se pertencente através da participação ideal e prática e do ser percebido pelos que estão próximos..." (HUBER, 1985, p. 35).

Em síntese, as organizações de economia social surgem a partir de uma redefinição do papel do Estado nas sociedades contemporâneas, onde a imobilidade do aparelho do governo é acompanhada por uma mobilidade por parte dos agentes sociais em todos os níveis, os quais se encontram orientados para a formação de uma sociedade menos desigual (ANDION, 2001; SALAMON, 1998; SERVA, 1997c).

Pinheiro (2003) procurou demonstrar como a literatura que abrange as temáticas do Terceiro Setor e a captação de recursos no Brasil tem se mostrado 
relacionada simplesmente ao aspecto financeiro, ao apresentar balanços, receitas, numa diversidade numérica onde, as soluções parecem adequadas, quando absorvidas dentro de concepções clássicas (industriais) da administração. O autor parte, assim, para o estudo do dom ou da dádiva (MAUSS, 2001a, MAUSS, 2001b, GODBOUT, 1999; GODELIER, 2001) na tentativa de dar significado às relações da sociedade com o setor em estudo, onde a base de sua sustentação seria a dimensão social e o pilar fundamental para a sustentabilidade financeira é construído a partir do momento em que há pessoas dispostas a contribuírem mutuamente; considerando-se, assim, a dádiva como elemento social fundamental para a busca de recursos.

A representatividade com que o trabalho voluntário tem ganhado importância em algumas organizações é um exemplo bem claro da importância social da voluntariedade, observado inclusive pela ótica da dádiva. Talvez o fato resida na importância que a atividade voluntária tem para o sustento de organizações que dependem muito da participação e da colaboração de seus membros. O trabalho voluntário, na análise feita por Andion (1998), mostra sentido e importância, sobretudo pela sua relação com as organizações estudadas, pelo seu caráter natural e independente. A importância desta dádiva amplia o espectro do ser voluntário e produz efeitos diretos para as organizações e para as pessoas que nelas atuam, gerando naturalmente a contradádiva, embora não solicitada explicitamente.

Pinheiro (2003) justifica a escolha de uma abordagem junto à dimensão social com os conceitos da sociologia econômica com foco no trabalho de Polanyi (1975) e os princípios da concepção substantiva da economia. Para Swedberg e Smelser (1994), a economia é vista como uma parte da sociedade, sendo esta a base de análise, ao contrário da concepção básica onde a economia é vista a partir da ótica do mercado, sobrepondo ao olhar da sociedade.

Para Polanyi (1975), o conceito de economia parte do princípio de que os meios são escassos, pois da relação do homem com a natureza apenas se evidenciarão os recursos necessários à subsistência primeira. $\mathrm{O}$ modo em que despenderá seus esforços e, portanto, o uso de sua racionalidade refere-se então à maneira pela qual o homem irá procurar maximizar esta sua relação com a natureza. Ramos (1989, p. 124), ao mencionar Polanyi, explana:

\footnotetext{
Nas sociedades não mercantis, as economias existiam no sentido substantivo..., a escassez de meios não constitui o princípio formal para a organização da produção e para a escolha humana de modo geral, uma vez que a sobrevivência do indivíduo é, normalmente, garantida pela eficácia dos critérios sociais globais (não da organização formal) de reciprocidade, redistribuição e troca. A economia, aqui, está incrustada na tessitura social, e não constitui um sistema autorregulado.
}

Os princípios da concepção substantiva da economia: redistribuição, reciprocidade e intercâmbio ou troca mercantil, destaca sua relação com a sustentabilidade da organização de economia social estudada por Polanyi (1975). Desta forma, é pertinente aprofundar o entendimento desta importante dimensão da racionalidade humana.

\section{Compreensão da Racionalidade Substantiva}

A compreensão sobre o conceito de racionalidade substantiva, assim como utilizada por Ramos em seus trabalhos ${ }^{2}$ também é fundamental para a análise proposta. Este conceito norteia inclusive a compreensão de homem parentético e, associado a 
outras noções contidas, principalmente em Serva (1996, 1997c), auxilia a compreensão do modelo fenonômico/isonômico no contexto das organizações substantivas e que tendem a modificar seus princípios racionais instrumentais.

Ramos (1989) propõe que as organizações sejam vistas sob a ótica da racionalidade, tendo para isto trazido à tona noções fundamentais contidas em Max Weber e em Karl Mannheim. Weber (1994), em seu livro Economia e Sociedade, constrói importantes conceitos sobre ação social ${ }^{3}$, que culminam em sua percepção de racionalidade, considerando-a como determinante da ação social. Para ele, existem quatro modos de a ação social a ser determinada: (a) de modo racional referente a meios-fim; (b) de modo racional referente a valores; (c) de modo afetivo, especialmente emocional; e (d) de modo tradicional.

O foco deste artigo considera os dois primeiros tipos que são as bases das racionalidades instrumental e substantiva, respectivamente. Ramos (1989) aborda a diferenciação conceitual que Weber utilizou entre racionalidade formal e racionalidade substantiva, esclarecendo e considerando a racionalidade substantiva como tendo sido "uma nota de rodapé em sua obra", no sentido de que não seria o objeto central de seus estudos. Em Weber, a racionalidade instrumental é definida como aquela cuja ação está direcionada para as relações meios-fim e a racionalidade substantiva seria aquela cuja ação está fundada em valores éticos, estéticos ou religiosos (WEBER, 1994; KALBERG, 1980).

Cabe aqui uma observação pertinente em relação ao crescente fenômeno de ações relativas à responsabilidade social corporativa na sociedade moderna (BRAGATO et al., 2008). A adesão a uma suposta racionalidade substantiva é de natureza duvidosa. Historicamente, as práticas administrativas tradicionais têm sido orientadas pela razão instrumental que, para Serva (1997c), seria um dos fatores que tem gerado condições degradantes do meio ambiente e das relações humanas. Segundo Weber (1994), a racionalidade instrumental é orientada pela ação social racional meios-fim, onde os processos mentais utilizam cálculo utilitário de consequências. A racionalidade é formal e prática e também há um padrão consciente de ação racional. De acordo com este tipo, o sentido racional da ação se encontra na escolha dos meios mais adequados para a realização de um fim. O único critério de seleção dos meios é a sua capacidade de realizar o objetivo estabelecido. Qualquer meio eficiente é válido tão somente por sua eficiência independentemente de avaliações morais ou éticas. É o tipo de ação mais freqüente na sociedade moderna. É a ação do empresário capitalista, é a ação do político que leu Maquiavel, é a ação do crime organizado e é a ação que se observou dramaticamente em Auschwitz.

O conceito de racionalidade substantiva tem na ética a sua regra de conduta para a vida social. Essa racionalidade, apoiada no pensamento aristotélico, transcende a relação entre razão e cálculo, permitindo que os indivíduos busquem a auto-realização e a satisfação social altruisticamente, através dos debates e do julgamento éticovalorativo. Isto é bem diferente do que se observa em organizações que adotam políticas de responsabilidade social apenas como uma forma de propaganda ou para maquiar irregularidades que não são controláveis.

Introduzir inadvertidamente a racionalidade substantiva como algo que está sendo incorporado pelo setor produtivo é no mínimo duvidoso. Ao analisarmos o conceito de racionalidade substantiva em Weber, esta falácia pode ser escancarada. Senão vejamos, esta racionalidade funda-se na ação social racional de valor, onde a realidade está subordinada a valores e existe um padrão consciente de racionalidade. A diferença em relação à ação racional meios-fim é que o fim é um valor que pode ter conteúdo ético, moral, religioso, político ou estético. O que dá sentido à ação é a sua 
racionalidade quanto aos valores que a guiam. A ação é orientada pela fidelidade aos valores que inspiram a conduta. Desde que fiel aos valores, o comportamento é válido por si mesmo. A "ação racional com respeito a valores" pode tender para a irracionalidade tanto mais quanto maior for a adesão aos valores absolutos. É a ação do crente que prefere pregar para as paredes a fazer alguma adaptação de suas ideias de acordo com o gosto do público. É a ação do artista que prefere não vender nenhuma obra a fazer concessões à platéia. É a ação do político que prefere perder as eleições a renegar a sua ideologia. É a ação do usineiro que concorda em reduzir os seus lucros para melhorar a qualidade do ar ao mecanizar a extração da cana e ainda assim gerar outros postos de trabalho em atividades diversificadas para manter a oferta de emprego. Isto é contraproducente e vai contra a lógica de otimização, eficiência e eficácia da modernidade.

Esta polêmica discussão remete ao pensamento do indiano Pavan Sukhdev (2010), economista sênior do Deutsche Bank, ao avaliar que o prejuízo causado pela destruição do ambiente só pode ser revertido com uma transição para um sistema econômico mais sustentável que ainda não está em vigor e deverá talvez levar algumas gerações para se estabelecer. Segundo ele, a visão dominante atual, é a da necessidade de escolher entre desenvolvimento e ambiente ou entre riqueza e biodiversidade. Esses elementos não são intercambiáveis. Os empresários também podem ser prejudicados pela devastação ambiental. Há pelo menos três maneiras de convencê-los disso. A primeira é mostrar os riscos crescentes ao seu negócio. Se a empresa atua no setor agrícola, por exemplo, pode ter gastos mais elevados com fertilizantes e até perder a capacidade de produzir em determinada região se houver escassez de água causada pelo mau uso dos recursos. A segunda maneira é revelar as oportunidades de negócio relacionadas à exploração sustentável da natureza. A indústria dos produtos orgânicos é um exemplo disso. Trata-se de um mercado que cresceu a um ritmo de $200 \%$ nos últimos quatro anos, no mundo todo. A terceira forma de eliminar a dicotomia entre desenvolvimento e ambiente é incentivar os empresários a explorar o potencial de uma nova área de inovação: a criação de tecnologias sustentáveis inspiradas em soluções da natureza. Em resumo, os empresários precisam começar a investir em capital natural, aquele formado pelos benefícios dos ecossistemas e da biodiversidade. Essa economia verde terá de substituir o modelo atual. Mas como convencer os agentes econômicos a adotar essa postura? Atualmente, os governos estão presos ao seguinte modelo: o crescimento do PIB influencia nos lucros corporativos, estes elevam o nível de arrecadação de impostos, que por sua vez alimenta o orçamento deficitário do Estado. Uma maneira de sair desse círculo vicioso é mudar a taxação de recursos. Em vez de arrecadar impostos sobre a renda e os bens, como é feito hoje, seria melhor taxar os efeitos externos negativos da atividade empresarial. As alíquotas deveriam ser aplicadas sobre o uso dos recursos naturais e materiais. O modelo atual apenas incentiva o mau uso do capital.

É a partir dessa perspectiva que se assiste ao surgimento do conceito de responsabilidade social corporativa que representa "alcançar sucesso comercial nas maneiras que honrem valores éticos e respeito às pessoas, comunidades e ambiente natural" (BUSINESS FOR SOCIAL RESPONSIBILITY, 2006). Esta perspectiva é ainda pouco aplicada pela maioria das empresas, mas vem ganhando espaço continuamente, conforme aponta pesquisa realizada conjuntamente pelo Instituto Ethos, Instituto Akatu e Ibope em 2008, que mostra um aumento de ações de responsabilidade social e ambiental por parte das empresas no Brasil.

O conceito econômico de externalidade é bem apropriado na análise, pois se refere a ações de alguns agentes que interferem no bem-estar dos demais, sem que haja 
a devida incorporação dos benefícios ou custos criados por parte dos responsáveis por essas ações. No primeiro caso, a externalidade é dita positiva e no segundo negativa (KNIGHT; YOUNG, 2006). A proposta de Sukhdev é taxar as atividades produtivas que geram externalidades negativas. A mudança de mentalidade que se orienta pelo incentivo a empreendimentos que não prejudiquem o tecido social e ambiental e que ao mesmo tempo sejam financeiramente viáveis, está ainda num processo inicial, uma vez que o discurso da responsabilidade social corporativa não tem um caráter transformador, consistindo apenas num deslocamento do capitalismo para combater as críticas, além de possibilitar uma nova forma de acumulação.

De modo geral, as ações de responsabilidade social têm cunho compensatório no que diz respeito ao público interno, portanto, têm como foco as externalidades provocadas nas relações de trabalho, e não necessariamente uma preocupação direta com aquelas que envolvem o ambiente da comunidade. Tal fator pode indicar duas possibilidades: ou consideram que o público interno é responsável significativo pela divulgação da imagem, ou não estão preocupados com o impacto das externalidades na comunidade em que se localizam. Ao analisar a relação entre as externalidades negativas provocadas e as ações compensatórias desenvolvidas, identificam-se algumas iniciativas. Contudo, essas não atendem à reversão do quadro de degradação provocado pela atividade produtiva.

Ramos (1989) utiliza em seu livro uma interessante linha de raciocínio com base em Herbert Simon ${ }^{4}$ e sua noção de racionalidade, passando por Chris Argyris, retomando as concepções de Aristóteles acerca de racionalidade, aprimorando em Karl Polanyi e Max Weber seu embasamento na diferenciação das concepções formais e substantivas de racionalidade.

Alguns autores percebem a proximidade da compreensão de racionalidade substantiva dada por Ramos a vários aspectos da chamada Teoria da Ação Comunicativa, de Habermas (1987a, 1987b). Serva (1997c, p. 22) utiliza os conceitos de Ramos e Habermas para definir a ação racional substantiva e a ação racional instrumental, explicitando os elementos que as constituem.

\section{Indivíduo Parentético, Racionalidade Substantiva e o Modelo Paraeconômico}

A hipótese básica do trabalho é a de que as organizações de economia social (ONGs) aproximam-se mais do modelo de isonomia e fenonomia sugerido pelo paradigma paraeconômico de Ramos (1989), o que leva a se inferir que seus membros encontram-se unidos mais pelos laços de solidariedade e ajuda ao próximo do que por retornos financeiros. Os conceitos e características de homem parentético, isonomia e fenonomia, segundo o autor, permitem verificar nas organizações que aparentemente se encaixam nesses modelos, como os indivíduos se comportam.

Os conceitos de ONG e terceiro setor são fundamentais para se identificar um cenário que se aproxime das proposições de Guerreiro Ramos. As ONGs fazem parte de um grupo de organizações que operam no denominado terceiro setor, constituem-se como pano de fundo, palco onde ocorrem as interações entre indivíduo e organização, sendo estas, hipoteticamente, organizações nas quais haja uma forte influência dos valores pessoais de seus participantes.

Segundo Ramos (1989, p. 177-178) existe diferentes esferas, que não a econômica, onde o indivíduo pode se realizar. $\mathrm{O}$ autor demonstra que as economias são consideradas apenas uma parte do conjunto da tessitura social, de forma que as isonomias e as fenonomias consistiriam outras esferas. Acrescenta ainda que o paradigma paraeconômico advoga uma sociedade suficientemente diversificada para 
permitir que seus membros cuidem de tópicos substantivos de vida, na conformidade de seus respectivos critérios intrínsecos e no contexto de cenários específicos a que esses tópicos pertencem.

A predominância de um dos dois tipos de racionalidade: instrumental ou substantiva, é que vai definir a especificidade de uma organização, bem como motivar o indivíduo a ter esta ou aquela orientação. Uma das reflexões a que o ensaio se propõe é verificar até que ponto um indivíduo se insere numa ONG? Para realização pessoal (racionalidade substantiva) ou por interesse econômico (racionalidade instrumental)?

\section{Paradigma Paraeconômico e o Homem Parentético}

$\mathrm{Na}$ sociedade contemporânea é evidente a orientação para uma lógica instrumental e utilitarista. Por conseguinte, aparentemente as ações dos gestores, bem como toda a teoria administrativa elaborada para estes, possuem basicamente uma orientação também instrumental/utilitarista. De acordo com Ramos (1989), essa lógica foi útil e necessária num período em que se necessitava superar a escassez de materiais e serviços, bem como promover o desenvolvimento econômico. Contudo, o erro das organizações está em admitir que estas antigas carências ainda são básicas, levando a um darwinismo social que tem validado recorrentemente a teoria e a prática administrativa.

Diante deste quadro, muitos têm sido os questionamentos e críticas acerca das conseqüências que a sociedade centrada no mercado tem acarretado para o homem. Surge então, um forte questionamento aos modelos de análise e planejamento de sistemas sociais que tem o mercado como o único ou o mais importante palco para as atividades humanas.

Ramos (1989) concebe um modelo de análise multidimensional, onde o paradigma paraeconômico considera o mercado um enclave legítimo e necessário, mas limitado. Nesse sentido, o autor busca defender, mediante a delimitação organizacional, um modelo que atenda a multidimensionalidade humana na formulação dos sistemas sociais.

Tendo em vista que o mercado considera recursos e produção apenas como insumos de atividades de natureza econômica, o modelo multicêntrico de alocação de recursos expande esta idéia, ao considerar tanto as atividades remuneradas quanto as não remuneradas, permitindo-nos vislumbrar o homem além de sua dimensão econômica, ou seja, em sua multidimensionalidade. O pressuposto fundamental desse paradigma é o deslocamento de uma sociedade centrada no mercado para uma sociedade multicêntrica, onde o mercado - politicamente regulado - ficaria restrito ao seu devido enclave social (RAMOS, 1989; SERAFIM, 2001).

O modelo multicêntrico de análise de sistemas sociais e de delineamento organizacional proposto por Ramos (1989) tem como objetivo contrapor ao modelo atual centralizado no mercado, partindo da premissa de que uma teoria da organização, cuja principal categoria é o mercado, não é aplicável a todos os tipos de atividades, mas apenas a um tipo especial. A proposta sugere uma delimitação do sistema de produção, de forma que este não alcança a vida completa do ser humano, uma vez que a organização formal não proporciona condições propícias para o autodesenvolvimento do mesmo.

Assim, partindo da multidimensionalidade do ser humano, a Teoria da Delimitação dos Sistemas Sociais propõe que os diferentes espaços da existência humana correspondam a cada uma de suas dimensões. Arendt (2001) trabalha com a 
concepção de espaços onde há a expressão do homem, incluindo sua noção de espaço público (esfera pública, como denomina a autora) que reúne os indivíduos, deixa-os em companhia uns dos outros e permite sua percepção de realidade.

De acordo com o modelo exposto por Ramos (1989, p. 146-53) na Teoria da Delimitação dos Sistemas Sociais, são seis as categorias do paradigma paraeconômico: (1) Anomia; (2) Motim; (3) Economia; (4) Isonomia; (5) Fenonomia; e (6) Isolado. A Figura 1 ilustra o paradigma paraeconômico com base na prescrição ou ausência de normas e na orientação comunitária ou individual.

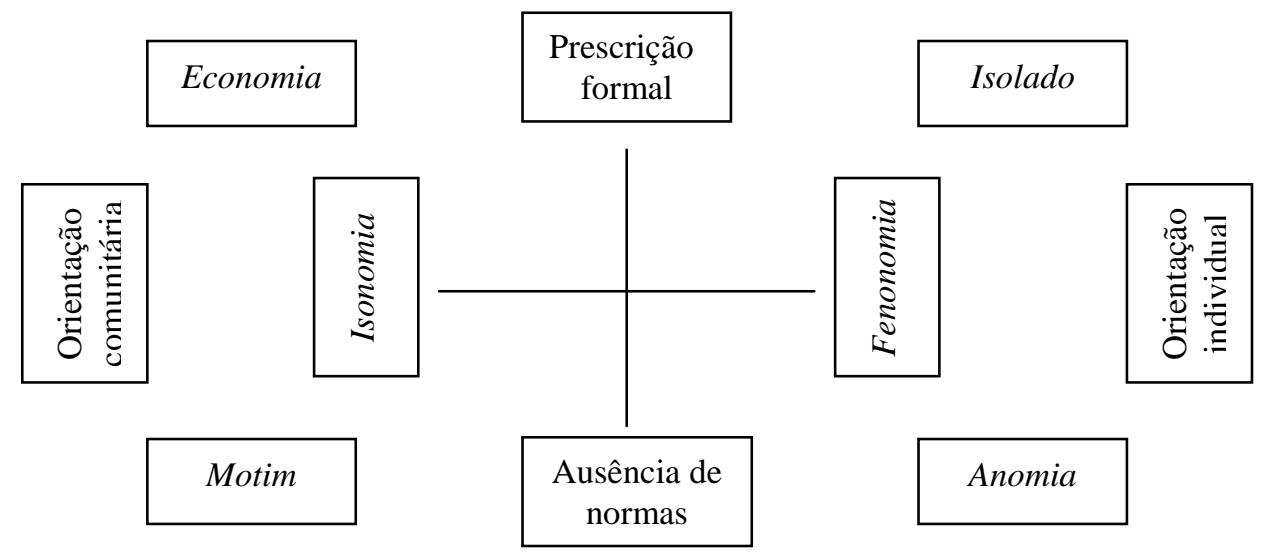

Figura 1 - O Paradigma Paraeconômico Fonte: adaptado de Ramos (1989, p. 141).

As presenças das categorias Anomia e Motim é exigida pela lógica das dimensões do paradigma. A Anomia é conceituada como uma situação estanque em que a vida pessoal e social desaparece e os indivíduos são desprovidos de normas e raízes, sem compromisso com prescrições operacionais. Motim é a referência de coletividades desprovidas de normas, a cujos membros falta o senso de ordem social. Em termos gerais, a Economia é um contexto organizacional altamente ordenado, estabelecido para a produção de bens e/ou para a prestação de serviços. A Isonomia (igualdade de normas) é definida como um contexto em que todos os membros são iguais. É uma oportunidade para o exercício mais igualitário de vivência, exercitando-se a convivialidade. A Fenonomia é um sistema social, de caráter esporádico ou mais ou menos estável, iniciado e dirigido por um indivíduo, ou por um pequeno grupo e que permite a seus membros o máximo de opção pessoal e um mínimo de subordinação a prescrições operacionais formais. O Isolado está excessivamente comprometido com uma norma que para ele é única e por uma série de razões, considera o mundo social incontrolável e sem remédio.

A relação entre o paradigma paraeconômico proposto por Ramos e as atividades desenvolvidas nas organizações de economia social parece clara a partir do momento em que a solidariedade só se estabelece num contexto que contemple a racionalidade substantiva. Fato este aparentemente possível num modelo de análise de sistema social que parta da premissa da multidimensionalidade do ser humano (RAMOS, 1989; SERVA, 1997c).

Apesar de ser na Economia que as pessoas detêm empregos e realizam trabalhos, elas raramente se ocupam. Esse fato torna-se evidente quando se considera que o "trabalho é a prática de um esforço subordinado às necessidades objetivas inerentes ao processo de produção em si", enquanto "a ocupação é a prática de esforços 
livremente produzidos pelo indivíduo, em busca de sua atualização pessoal" (RAMOS, 1989, p. 130). Já o emprego se constitui num posto de trabalho formal junto a uma organização ou a uma pessoa, dentro do escopo do mercado. Essa relação formal se estabelece entre organizações e pessoas e, nela, estas são detentoras de um emprego. Os efeitos que o emprego exerce sobre a vida humana em geral são alienantes, transformando o ser humano em vítima patológica da sociedade centrada no mercado (RAMOS, 1989, p. 98-108).

Desta forma, os espaços sociais que permitiriam a utilização da racionalidade substantiva em sua plenitude seriam, no modelo paraeconômico de Guerreiro Ramos, a Isonomia e a Fenonomia, adequadas à plena possibilidade de ação do homem parentético. As organizações de economia social, em sua maioria, possuem características que as aproximam das isonomias. As principais características de uma isonomia são: (1) possui o objetivo essencial de permitir a atualização de seus membros, independentemente de prescrições impostas; (2) o espaço da isonomia possui um caráter autogratificante, pois os indivíduos que nele livremente se associam desempenham atividades compensadoras em si mesmas; (3) as atividades promovidas neste contexto são promovidas como vocações, não como empregos. Nelas, a recompensa básica do indivíduo está na realização dos objetivos intrínsecos daquilo que faz, não na renda eventualmente auferida por sua atividade; (4) a isonomia é como uma verdadeira comunidade, onde a autoridade é atribuída por deliberação de todos, ou seja, não há diferenciação entre liderança ou a gerência e os subordinados; e (5) sua eficácia exige que prevaleçam entre seus membros relações interpessoais primárias. Caso eventualmente se desenvolva relacionamentos secundários em decorrência do aumento de tamanho da isonomia, esta tende a declinar-se na medida em que, necessariamente se transformará numa democracia, oligarquia ou numa burocracia.

Já o espaço da Fenonomia (do grego phaineim = mostrar) caracteriza-se como uma oportunidade para o exercício da realização pessoal. Deve ser entendida como um estado de busca permanente, já que é próprio do ser humano dar significado à vida. Por isso, pode-se afirmar que a fenonomia é uma oportunidade de realizar algo que preencha a lacuna o sentido de sua existência (SERAFIM, 2001).

Portanto, a fenonomia constitui-se como um ambiente necessário às pessoas para a liberação de sua criatividade e segundo maneiras escolhidas com plena autonomia. Seus membros empenham-se apenas em obras automotivadas, o que significa que, de modo geral, se mantêm altamente ocupados e seriamente comprometidos com a consecução daquilo que consideram importante. As fenonomias são cenários sociais protegidos contra a penetração do mercado e, portanto, os critérios econômicos são incidentais em relação à motivação de seus membros. Embora interessado em sua própria individualidade, o membro desse espaço tem consciência social. Sua opção visa tornar outras pessoas sensíveis quanto a possíveis experiências que são capazes de partilhar ou apreciar. Em suma, o exercício de qualquer atividade que engrandeça, que possa ser classificado como nobre ou que proporcione o sentimento de satisfação íntima, pertence ao espaço fenonômico. Exemplos são as atividades relacionadas com as artes, alguns trabalhos intelectuais e o trabalho em prol do bem comum.

As categorias expostas do paradigma paraeconômico pressupõem que, em cada um desses espaços, projeta-se um modelo de ser humano. Este trabalho refere-se a cada um dos tipos, dando especial ênfase à tipologia do homem parentético adotada também no trabalho de Ramos.

O homem operacional, por sua vez, se caracteriza por buscar apenas sua subsistência em termos de necessidades básicas, tanto as de natureza primária quanto as 
sociais mais elementares. (SERAFIM, 2001). Ele tem sido considerado um recurso organizacional a ser maximizado em termos de produto físico mensurável. De acordo com Ramos (1984), as demais características do homem operacional são: constitui-se como um ser passivo, que deve ser programado, via treinamento, para atuar dentro da organização; possuir motivação para o trabalho com vistas a obter um retorno econômico e material; a ausência de preocupação ética associada ao trabalho; a ausência de liberdade pessoal no âmbito do espaço da economia; a ausência de recompensa intrínseca no exercício do trabalho, tendo como consequiência a satisfação postergada. $O$ espaço do homem operacional corresponde, em larga escala, à economia.

O modelo de homem reativo é fruto de uma nova visão da motivação e da constatação da influência de seus sentimentos e valores no espaço de produção econômica ou organizacional (SERAFIM, 2001). Contudo, os objetivos buscados não foram realmente alterados, em relação ao modelo do homem operacional. De acordo com Ramos (1984, p. 6) "seu principal objetivo era o ajustamento do indivíduo ao contexto de trabalho e não seu crescimento individual. $O$ resultado final de utilização excessiva de relações humanas foi a total inserção do trabalhador e não seu crescimento pessoal".

O homem reativo pode ser definido como um indivíduo que se adapta às normas do grupo institucional pela subordinação aos ditames do grupo informal e adaptabilidade ao meio. Constitui uma categoria que expressa a adaptabilidade e a sociabilidade do ser humano, imergindo-o no grupo e subordinando-o a ele. $\mathrm{O}$ espaço do homem reativo é a economia e a burocracia, ou seja, o ambiente de massas ou grupos sociais maiores. Ele também pode pertencer, eventualmente, aos espaços isonômicos ou conviviais (SERAFIM, 2001).

O homem parentético é a concepção do ser humano na dimensão lúcida da razão (SERAFIM, 2001). Caracteriza-se por ter uma participação ativa nas organizações, uma vez que não pode ser psicologicamente enquadrado como aquele indivíduo que se comporta de acordo com os modelos reativo e operacional; possui uma consciência crítica altamente desenvolvida das premissas de valor presentes no dia-adia; está apto a compreender os ditames da razão substantiva, em contraposição às condicionantes do comportamento definidas a partir das imposições externas; está apto a examinar e avaliar permanentemente, o espaço da vida diária como um espectador; isso devido à sua capacidade de romper com suas próprias raízes; e considerar-se como que em suspenso (em parênteses) no seu meio social. O homem parentético constitui uma categoria que expressa a autonomia e a atividade (no sentido contrário ao da passividade). Os espaços em que ele encontra plena possibilidade de ação é o da fenonomia e o da isonomia.

Guerreiro Ramos associa os modelos de homem às dimensões da razão. Dessa forma, o homem operacional se fundamenta na dimensão biológica ou física; o homem reativo na dimensão social; e o homem parentético se firma na dimensão política. Cabe lembrar que é necessária a presença destes modelos em cada ser humano, pois sem elas, ele perde sua característica de humanidade, passando à condição de unidimensionalidade, restrita ao âmbito econômico (RAMOS, 1984; SERAFIM, 2001).

\section{Princípio do Prazer e do Sofrimento no Trabalho}

Esta seção busca ampliar a discussão e explorar outras possibilidades que podem ser investigadas numa pesquisa empírica sobre fenonomia e isonomia. Se a concepção de homem parentético se enquadra como modelo no sistema fenonômico/isonômico, 
isto pode explicar o relativo estado de infelicidade do individuo no modelo econômico. A constatação parece óbvia, mas cabe a validação por meio da coleta de dados e do teste de hipóteses, pois a visão de homem econômico é parcial e não contempla toda a dimensão humana.

O trabalho é geralmente o meio pelo qual o homem se relaciona com o mundo exterior, onde, permanentemente, busca o prazer e luta contra o sofrimento. Resulta desse embate vivências que determinam a qualidade das relações em todos os aspectos de sua existência. Assim, o trabalho, com seus elementos causadores de prazer e sofrimento, constitui-se numa atividade decisiva para o equilíbrio psíquico do indivíduo e para o desenvolvimento da comunidade que integra, influenciando-se mutuamente. (OLIVEIRA e MAZZILLI, 1997).

Segundo Dejours (1996, p. 153-154), as pressões do trabalho, que põem em causa o equilíbrio psíquico e a saúde mental, derivam da organização do trabalho, ou seja, da divisão das tarefas que atinge diretamente a questão do interesse e do tédio no trabalho; de outra parte, a divisão dos homens (hierarquia, comando, submissão), que atinge diretamente as relações que os trabalhadores estabelecem entre si no local de trabalho.

De acordo com Ciampa (1993), a atividade social concretiza a identidade dos indivíduos, tornando a análise da representação do trabalho essencial para compreendêla. Juntamente com a atividade, é de grande importância a análise das relações sociais e da consciência como categorias essenciais da identidade.

Chanlat (1995) identifica quatro principais métodos de gestão atuais que não contemplam os ideais parentéticos, e que estão resumidos abaixo:

1) $\mathrm{O}$ modo de gestão taylorista e neotaylorista, que inclui o modelo fordista e o volvismo, caracterizado principalmente por uma divisão do trabalho muito fragmentada, produção sob premência de tempo, tarefas repetitivas, modos de remuneração segundo o rendimento, rigidez de horários, separação e direito de expressão muito reduzido, e até nulo, divisão entre a concepção e a execução e sistemas de controle muito elaborados.

2) $\mathrm{O}$ modo de gestão tecnoburocrático que se caracteriza por um pirâmide hierárquica desenvolvida, divisão do trabalho parcelada, regulamentação escrita onipresente, grande importância aos especialistas e técnicos, controles muito sofisticados, comunicação difícil entre os escalões da empresa, centralização do poder, autonomia relativamente fraca para os patamares inferiores e um direito de expressão muito limitado.

3) $\mathrm{O}$ modo de gestão baseado na excelência (ou qualidade total) que engloba as novas práticas administrativas, baseando-se na noção de produzir melhor que os concorrentes, enfatiza o primado do êxito, a supervalorização da ação, a obrigação de ser forte, a adaptabilidade e desafio permanentes, a canalização da energia individual nas atividades coletivas, uma maior autonomia no trabalho, recompensas materiais e simbólicas individualizadas, relações hierárquicas mais igualitárias, flexibilidade, polivalência da mão-de-obra e um recrutamento seletivo.

4) $\mathrm{O}$ modo de gestão participativo que reagrupa todas as experiências de gestão que fazem com que o pessoal de uma organização participe em diversos níveis. Parte do princípio de que o ser humano é responsável à qual se deve conceder toda a autonomia necessária para a realização da tarefa para, na verdade, integrá-la na gestão mais global da empresa sem levar em conta as necessidades individuais.

O impacto da racionalidade instrumental sobre o comportamento do indivíduo está presente em todos os modos de gestão descritos por Chanlat. O homem moderno (econômico) passou a conviver com as várias formas de racionalidades, contudo a que comanda é a lógica instrumental. O indivíduo deve se habituar com os avanços das 
ciências e, consequentemente, com a racionalidade científica. Ao mesmo tempo, ele está vinculado, quase sempre, a uma lógica predominantemente de ordem religiosa, herança de uma transformação ao longo da história, com seu início, antes mesmo, da Idade Média. Assim, existem tantas racionalidades quanto possíveis para explicar o mundo em que vivemos. Contudo, a convivência com estas formas de encarar o mundo gera uma instabilidade crescente com o princípio do prazer.

Conceitualmente, segundo Freud (1997), este é um dos dois princípios que regem o funcionamento mental: a atividade psíquica no seu conjunto tem por objetivo evitar o desprazer e proporcionar o prazer. "É um princípio econômico na medida em que o desprazer está ligado ao aumento das quantidades de excitação e o prazer à sua redução" (LAPLANCHE e PONTALIS, 1997, p. 364). O segundo conceito, o princípio de realidade, "forma par com o princípio de prazer e modifica-o; na medida em que consegue impor-se como princípio regulador; a procura de satisfação já não se efetua pelos caminhos mais curtos, mas faz desvios e adia o seu resultado em função das condições impostas pelo mundo exterior" (LAPLANCHE e PONTALIS, 1997, p. 368).

O discurso da sociedade moderna promete, tantas vezes quanto for possível, a realização de objetivos embutidos por ela mesma por meio da ideologia dominante. A busca desta realização dos objetivos é uma promessa da realização do princípio do prazer, onde o indivíduo canaliza todos os seus desejos de realizações narcísicas e coletivas. Contudo, tais objetivos não passam de articulações criadas no plano da fantasia, onde há uma impossibilidade de realizações na própria essência do objeto. Vejamos o exemplo do trabalho: na maioria das sociedades industriais o trabalho adquiriu o status de valor social a ser praticado, onde a disciplina e a dedicação máxima são prerrogativas para o sucesso individual. Cria-se, nas representações compartilhadas, uma proibição e, conseqüentemente, uma punição a todos aqueles que eventualmente não obtiverem o sucesso profissional e financeiro imaginado anteriormente na sociedade. O que se institui, portanto, é um sentimento de "não é permitido perder" (SENNET, 1999). Assim, o local onde seria a realização do homem, torna-se o seu local de sofrimento (DEJOURS et al., 1994).

O que permeia na atualidade é a predominância do princípio de prazer fictício na sua totalidade, prometendo, desta forma, um futuro de prazer a ser atingido. Esta situação se dissimula em todas as esferas sociais, cada qual a sua maneira e com graus de intensidades diferenciados. Há, assim, um conflito estabelecido entre a busca do prazer e suas reais condições de realização. O que se discursa, hoje em dia, é que a sociedade moderna é capaz, através do progresso tecnológico nas diversas áreas do conhecimento, de criar situações favoráveis às realizações do princípio de prazer. Esta perspectiva é levada a uma incongruência na medida em que cada indivíduo, na busca de tais objetivos, se depara com as limitações da própria realidade criada por ele a partir das fases ilusórias estabelecidas. Mais uma vez, percebe-se que o imaginário torna-se enganador (ENRIQUEZ, 1997), na medida em que, também no âmbito da sociedade como um todo, há uma promessa instituída que não pode ser cumprida.

Com a supressão dos instintos e desejos humanos - aqueles mesmos reportados por Freud (1997) no processo de criação e manutenção da ordem social, descritos na sua obra intitulada "O Mal-Estar na Civilização", não há perspectivas para os indivíduos de uma liberdade incondicional, motivada pelos processos inconscientes e particulares a cada um.

De acordo com Dejours et al. (1994), o trabalho em si não traz sofrimento, mas sim a forma como ele está organizado. Entre a organização prescrita do trabalho e o seu desenvolvimento existe um espaço de liberdade que possibilita uma negociação do modo operatório do trabalho pelo trabalhador, adaptando a organização do trabalho às 
suas necessidades. A Psicodinâmica do Trabalho é, portanto, uma crítica à teoria da Síndrome Geral de Adaptação que não questiona a forma de organização do trabalho, visualizando o sofrimento como um processo de adaptação individual e não permeado por relações sociais. $\mathrm{O}$ trabalho se torna perigoso quando se opõe à livre atividade prevista pelo modelo isonômico/fenonômico. Desejo de trabalhar contra a vontade do empregador é a contradição fundamental que comanda a carga psíquica do trabalho.

Assim, a hipótese que se levanta é que este quadro configurado por Dejours, Ciampa e Chanlat, Freud e Sennet não se estabeleceria se as pessoas se realizassem com o trabalho. Ou seja, são raros os casos de pessoas que fazem o que realmente gostam com prazer e recebem uma compensação financeira à altura de suas necessidades. A maioria das pessoas se ocupa não porque realmente são vocacionadas, mas porque precisam da remuneração do trabalho que conseguiram para sobreviver. No nível individual ocorre a aceitação deste modelo que é projetado no sistema vigente. Os indivíduos não têm alternativas e se sujeitam a este sistema de dominação.

Muitos indivíduos ao se aposentarem, começam a pensar na realização de seu ideal parentético e passam a atuar em organizações de economia social de forma voluntária. Um aspecto interessante a se investigar é a co-relação entre idade e gestor destas organizações e/ou de seus membros para confirmar esta tendência e os motivos que levam a isso.

\section{Considerações Finais}

É provável que o modelo dominante de sistema social da modernidade seja o econômico em praticamente todos os setores da sociedade. Contudo, esta predominância não ocorre de maneira uniforme e há matizes variadas de influências isonômicas e fenonômicas. Segundo Serva (1996), é possível analisar isto num continuum, bastando estabelecer os parâmetros para se investigar as organizações. Para tanto, é necessário estabelecer uma agenda de pesquisa que busque investigar até que ponto a racionalidade substantiva prevalece nas organizações de economia social e como isto afeta as ações estratégicas dos diversos setores da economia, tendo em vista as pressões institucionais ligadas à garantia do bem-estar das gerações futuras. Será que estas organizações realmente se aproximam do modelo de isonomia e fenonomia sugerido pelo paradigma paraeconômico de Guerreiro Ramos? A Teoria da Delimitação dos Sistemas Sociais deste autor aparentemente ajuda a responder esta questão.

A análise também pode recorrer à noção de quais práticas estão sendo adotadas nas sociedades num movimento de transformação social que poderá culminar com novos modelos sociais. A combinação isonomia com fenonomia é desejável, porém numa sociedade fundada na racionalidade instrumental, não ocorrerá em estado puro. As pressões ambientais e sociais sinalizam nesta direção e as organizações que não levarem isso em conta, poderão ter sérios problemas de sobrevivência em longo prazo. A maioria dos recursos que são fontes de energia, por exemplo, estão se esgotando e a inflexão na direção do desenvolvimento sustentável é inevitável.

Muito embora a noção de indivíduo parentético tenha sido apresentada em plano teórico, sua discussão é pertinente a partir do momento em que se percebe uma demanda na própria sociedade por novos arranjos organizacionais, ou ainda, em que se pretenda a prática numa sociedade multicêntrica. Organizações, que trabalham com modelos de gestão mais focados para a prática social do que necessariamente para valores instrumentais, têm exigido processos de gestão diferenciados, como pode ser observado, por exemplo, nas extensas discussões sobre gestão de organizações de economia social. 
Neste sentido, é importante observar a discussão acerca da tensão entre as racionalidades substantiva e instrumental no trabalho de Santos (2012). Esta reflexão é primordial para a compreensão deste indivíduo e de seu papel nestas organizações. Percebe-se que a dimensão social da sustentabilidade (PINHEIRO, 2003) é explicada não somente pelas conexões, mas também, pela própria característica do indivíduo que sublima os princípios econômicos tradicionais, agregando valores individuais e a capacidade de admitir aquilo que é importante para si e para o fim social da organização.

O paradigma paraeconômico de Guerreiro Ramos se revela muito útil para se realizar análises das organizações modernas e identificar novas tendências e estruturas sociais. É pertinente ir a campo para se constatar a validade dos pressupostos aqui levantados e ampliar a discussão com a obtenção de dados empíricos. É fato que o presente ensaio se limita a algumas reflexões a respeito da evolução das formas organizacionais, levando em conta a natureza humana, mas busca compartilhar ideias com o meio acadêmico para novas possibilidades de pesquisa sobre esta relevante temática.

Pelas discussões trazidas neste artigo, é possível também admitir o conceito de indivíduo parentético ligado às organizações que trabalham sobre preceitos que vão além da razão instrumental e, portanto, sugere-se buscar outras questões acerca deste indivíduo em ações de voluntariado, práticas de sustentabilidade ou ainda, em organizações com forte ligação com temáticas socioambientais, movimentos sociais ou relações de cooperação, comunhão ou forte engajamento social como fundamento.

No nível do indivíduo, por exemplo, a noção de homem operacional, reativo e parentético, abre oportunidades para investigações qualitativas fenomenológicas que busquem explicar o comportamento humano na esfera econômica predominante no mundo moderno, procurando identificar diferenças entre indivíduos que atuam em organizações puramente econômicas e de economia social.

Além disso, outra oportunidade de trabalho futuro é investigar se o perfil de homem parentético realmente está presente em organizações de economia social e, uma vez identificado, constatar se um novo modelo social de gestão, que não o centrado em princípios puramente econômicos, como os identificados por Chanlat (1995), pode então ser apreciado e configurado. Assim, será possível visualizar até que ponto o indivíduo parentético explica a dimensão social da sustentabilidade em organizações de economia social.

\section{Notas}

\footnotetext{
${ }^{1}$ Neste trabalho foi utilizado o termo "Organização de Economia Social" em substituição ao termo "Organização Não-Governamental".

${ }^{2}$ Para a noção completa, ver Ramos (1983) e (1989) citado nas referências bibliográficas deste ensaio.

${ }^{3}$ Weber (1994, p.13-14) diferencia a ação social da ação externa, de modo a esclarecer que "nem todo tipo de ação - também de ação externa - é ação social" no sentido aqui adotado. A ação externa, por exemplo, não o é, quando se orienta exclusivamente pela expectativa de determinado comportamento de objetos materiais. O comportamento interno só é ação social quando se orienta pelas ações de outros (itálico nosso)". Sendo assim, considera-se que "a ação social (incluindo omissão ou tolerância) orientase pelo comportamento de outros, seja este passado, presente ou esperado como futuro".

4 Simon considera a racionalidade como o "conhecimento absoluto de conseqüências". Simon (1965) apud Ramos (1989, p. 121).
} 


\section{Referências}

AKTOUF, O. A administração entre a tradição e a renovação. São Paulo: Atlas, 1996.

ANDION, C. As particularidades da gestão em organizações da economia solidária. In: XXV EnAnpad, Anais Campinas: ANPAD, 2001.

. La gestion dês organisations de l'economie solidaire: deux etudes de cas à Montreal'. Dissertação de Mestrado. Montreal: École dês Hautes Études Commerciales affiliée à l'Université de Montreal, 1998.

ARENDT, H. A condição humana. 10 ed. Rio de Janeiro: Forense Universitária, 2001. BOYD, H. W. et al. Marketing research: text and cases. Homewood: R. D. Irwin, 1989.

BRAGATO, I. R.; SIQUEIRA, E. S.; GRAZIANO, G. O.; SPERS, E. E. Produção de açúcar e álcool vs. responsabilidade social corporativa: as ações desenvolvidas pelas usinas de cana-de-açúcar frente às externalidades negativas. Gest. Prod., São Carlos, v. 15, n. 1, p. 89-100, jan.-abr. 2008.

BUSINESS FOR SOCIAL RESPONSIBILITY. Corporate social responsibility. Disponível em: <http://www.bsr.org/AdvisoryServices/CSR.cfm>. Acesso em: 22 fev. 2006.

CHANLAT, J. F. Modos de gestão, saúde e segurança no trabalho. In: DAVEL, E.; VASCONCELOS, J. M. (Orgs.). Recursos humanos e subjetividade. Petrópolis: Vozes, p. 118-126, 1995.

CIAMPA, A. C. A estória do Severino e a história da Severina: um ensaio de psicologia social. 3. ed. São Paulo: Brasiliense, 1993.

DEJOURS, C.; ABDOUCHELLI, E; JAYET, C. Psicodinâmica do trabalho. São Paulo: Atlas, 1994.

DEJOURS, C. Sofrimento, Prazer e Trabalho. In: Identidade, reconhecimento e transgressão no trabalho: conferências brasileiras. São Paulo: Edições Fundap (EAESP-FGV), 1994.

. Uma nova visão do sofrimento humano nas organizações. In: CHANLAT, J. F. O indivíduo na organização. v. 3. São Paulo: Atlas, 1996.

ENRIQUEZ, E. A organização em análise. Vozes: Petrópolis, 1997.

FERNANDES, R. C. Privado, porém público: o terceiro setor na América Latina. Rio de Janeiro: Civicus, 1994.

FISHER, R. M; FALCONER, A. P. Desafios da parceria governo e terceiro setor. Revista de Administração USP. São Paulo, v. 33, n. 1, p. 12-19, jan./mar. 1998.

FRAGA, M. L. A empresa produtiva e a racionalidade substantiva: a teoria da ação comunicativa de Jürgen Habermas no ambiente organizacional integrativo, de Mary Parker Follett a Collins e Porras. Dissertação de Mestrado. Universidade Federal do Rio Grande do Sul. Porto Alegre, 2000.

FREUD, S. O mal-estar na civilização. Rio de Janeiro: Imago, 1997.

GODBOUT, J. T. O espírito da dádiva. Rio de Janeiro: FGV, 1999.

GODELIER, M. O enigma do dom. Rio de Janeiro: Civilização Brasileira, 2001.

GONÇALVES, H. S. (Org.). Organizações não governamentais: solução ou problema. São Paulo: Estação Liberdade, 1996.

INSTITUTO ETHOS; INSTITUTO AKATU; IBOPE INTELIGÊNCIA. Práticas e perspectivas da responsabilidade social empresarial no Brasil. São Paulo, 2008.

HABERMAS, J. Teoría de la acción comunicativa: racionalidad de la acción y racionalización social. Madrid: Taurus, 1987a. Tomo I. 
Teoría de la acción comunicativa: crítica de la razón funcionalista. Madrid: Taurus, 1987b. Tomo II.

HUBER, J. Quem deve mudar todas as coisas: as alternativas do movimento alternativo. Rio de Janeiro: Paz e Terra, 1985.

JERÔNIMO, F. B; MACHADO, M. Y. O. T; MARASCHIN, A. F. A gestão estratégica das sociedades cooperativas no cenário concorrencial do agronegócio brasileiro: um estudo de caso em uma cooperativa agropecuária gaúcha. In: XXVIII EnANPAD. Anais. Curitiba: ANPAD, 2004.

KALBERG, S. Max Weber's types of rationality: cornerstones for the analysis of rationalization process in history. American Journal of Sociology, v. 85, n. 5, p. 1145$1179,1980$.

KNIGHT, V. M.; YOUNG, C. E. F. Custo da poluição gerada pelos ônibus urbanos na RMSP. In: ANPEC, 34, 2006, Salvador. Disponível em: <http://www.anpec.org.br/ encontro2006/ artigos/A06A069.pdf>. Acesso em: 15 maio 2007.

LANDIM, L. Notas para um perfil das ONGs: as pertencentes à Associação Brasileira de ONGs. Rio de Janeiro: ISER, 1994.

LANDIM, L; DURÃO, J. E. S. A criação de um novo marco legal para o terceiro setor no Brasil. Disponível em: www.abong.org.br/novosite/download/Landim_Durao.doc. Acesso em: 30 ago. 2010.

LAPLANCHE, J.; PONTALIS, J. B. Vocabulário da psicanálise. São Paulo: Martins Fontes, 1997.

MAUSS, M. Ensaios de sociologia. São Paulo: Perspectiva, 2001a.

Ensaio sobre a dádiva. Lisboa: Edições 70, 2001b.

OLIVEIRA, M. J. S.; MAZZILLI, C. O significado do trabalho no setor público: um estudo exploratório. In: XXI EnAnpad, Anais, Rio das Pedras: ANPAD, 1997.

PINHEIRO, D. M. Sustentabilidade de ONG's: um estudo de caso na organização AFECE - Associação Franciscana de Educação ao Cidadão Especial. Dissertação de Mestrado. Universidade Federal do Paraná. Curitiba, 2003.

POLANYI, K. L'économie em tant que procès institutionnalisé. In: POLANYI, K. e ARENSBERG, C. (Orgs.) Les systèmes économiques dans l'histoire et dans la théorie. Paris, Larousse, 1975.

RAMOS, A. G. A nova ciência das organizações: uma reconceituação da riqueza das nações. 2 ed. Rio de Janeiro: FGV, 1989.

Modelos de homem e teoria administrativa. Revista de Administração Pública, Rio de Janeiro, v. 18, n. 2, p. 3-11, abr./jun. 1984.

Administração e contexto brasileiro: esboço de uma teoria geral da administração. Rio de Janeiro: FGV, 1983.

SALAMON, L. A. emergência do terceiro setor: uma revolução associativa global. Revista de Administração da USP. São Paulo, v. 33, n. 1. p. 5-11, jan./mar. 1998.

SAMPIERI, R. H.; COLLADO, C. F.; LUCIO, P. B. Metodología de la investigación. México: McGraw-Hill, 1991.

SANTOS, J. V. T. A construção da viagem inversa. Cadernos de Sociologia, ensaio sobre a investigação nas ciências sociais, Porto Alegre, v. 3, n. 3, p. 55-88, jan./jul. 1991.

SANTOS, L. S. A Tensão entre a racionalidade substantiva e a racionalidade instrumental na gestão pública: novos caminhos de um campo de estudos. Dissertação (Mestrado) - Universidade Federal de Santa Catarina. Programa de Pós-Graduação em Administração. Florianópolis, 2012.

SENNETT, R. A corrosão do caráter: conseqüências pessoais do trabalho no novo capitalismo. Rio de Janeiro: Record, 1999. 
SERAFIM, M. C. Considerações acerca da solidariedade no espaço de produção para uma efetiva concretização de alternativas. Revista Urutágua da UEM. Maringá, ano 1, n. 3, dez./2001.

SERVA, M. Racionalidade e Organizações: o fenômeno das organizações substantivas. Volumes I e II. São Paulo: FGV, 1996. Tese de Doutorado em Administração, Escola de Administração de Empresas de São Paulo, FGV, 1996.

O Estado e as ONG's: uma parceria complexa. Revista de Administração Pública. Rio de Janeiro, FGV, v. 31, n. 6, nov./dez. 1997a.

Abordagem substantiva e ação comunicativa: uma complementaridade proveitosa para a teoria das organizações. Revista de Administração Pública. Rio de Janeiro, FGV, v. 31, n. 2, mar./abr. 1997b.

A racionalidade substantiva demonstrada na prática administrativa. Revista de Administração de Empresas. São Paulo, v. 37, n. 2, abr./jun. p. 18-30. 1997c.

SUKHDEV, P. O preço da biodiversidade. Disponível em <http://veja.abril.com.br/090610/ preco-biodiversidade-p-156.shtml> Acesso em: 26 ago. 2010.

SWEDBERG, R.; SMELSER, N. J. (Orgs.). The handbook of economic sociology. NJ: Princeton University, 1994.

TRIPODI, T.; FELLIN, P.; MEYER, H. Análise da pesquisa social. Rio de Janeiro: Francisco Alves, 1975.

WEBER, M. Economia e sociedade: fundamentos da sociologia compreensiva. 3 ed. Brasília: UNB, 1994. 